\title{
Imunossenescência: a relação entre leucócitos, citocinas e doenças crônicas
}

\author{
Immunosenescence: the association between leukocytes, cytokines and chronic
}

diseases

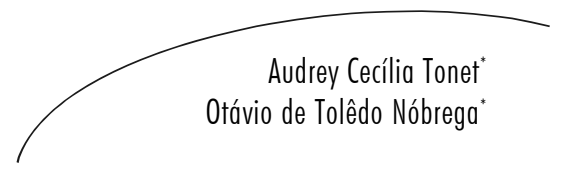

\section{Resumo}

O processo de envelhecimento e sua conseqüência natural - a velhice constituem uma das maiores preocupações da sociedade moderna, sobretudo devido ao rápido crescimento da parcela idosa da população com relação aos demais grupos etários. Esse crescimento traz mudanças para nossa civilização e desafia a sociedade em diferentes aspectos, especialmente naqueles relativos à saúde humana. Este último talvez seja o mais enfatizado e preocupante, já que a maioria dos idosos apresenta ao menos uma doença crônica e limitações de saúde. Sob o caráter biológico, o processo de envelhecimento é um fenômeno complexo que submete o organismo a inúmeras alterações fisiológicas, afetando sua integridade e permitindo o surgimento das doenças crônicas na velhice, com impacto sobre a saúde e a qualidade de vida do idoso. Dentre os sistemas do organismo, os que mais sofrem efeitos do envelhecimento são o nervoso, o endócrino e o imunológico. Nesta revisão, o processo de envelhecimento é abordado sob a ótica das alterações do sistema imunológico conhecidas como o fenômeno da imunossenescência. São analisados aspectos relacionados a alterações numéricas, morfológicas e funcionais dos diferentes tipos celulares que compõem o sistema, com ênfase para os efeitos biológicos dos principais mediadores inflamatórios (citocinas) para o surgimento das doenças crônico-degenerativas presentes no envelhecimento.

\footnotetext{
"Universidade Católica de Brasília, Laboratório de Imunogerontologia Programa de Pós-Graduação Stricto Sensu em Gerontologia Brasília, DF, Brasil

Correpondência / Correspondence

Otávio de Tolêdo Nóbrega,

Universidade Católica de Brasília

Programa de Pós-Graduação Stricto Sensu em Gerontologia - Sala B-105

Campus I - Q.S. 07 Lote 1 EPCT

72030-170 - Brasília, DF, Brasil

E-mail: nobrega@ucb.br
}

\author{
Palavras-chave: \\ envelhecimento; \\ sistema imune; \\ síndromes de \\ imunodeficiência; \\ sistema nervoso; \\ sistema endócrino; \\ doença crônica; \\ processos fisiológi- \\ cos; revisão
}


Abstract

The aging process and its natural consequence - oldness - are one of the major concerns of modern society, especially due to the rapid growth of the elderly population when compared to other age groups. This particular growth brings about significant changes in our civilization and also challenges society in several aspects, especially in those concerning health issues. This latter aspect is probably the most emphasized and worrisome, since a large proportion of older-adults bear at least one chronic disease or health restrictions. Regarding biological features, the aging process is a complex phenomenon that submits the organism to several physiological alterations, affecting its integrity and allowing the manifestation of chronic illnesses in old-age, with impact in the elder's health and quality of life. Among the systems of the organism, the nervous, endocrine and immune systems suffer more changes as one grows old. This literature review deals with the aging process in view of alterations of the immune system known as immunosenescence. It will analyze aspects related to numerical, morphological and functional alterations of different cell types that form the system, with emphasis to the biological effects of the major inflammatory mediators (citokines) in the onset of chronic-degenerative diseases inherent to the aging process.
Key words: aging; immune system; immunologic deficiency syndromes; nervous system; endocrine system; chronic disease; physiological processes; review

\section{O PROCESSO DE ENVELHECIMENTO}

O envelhecimento populacional é, hoje, um proeminente fenômeno mundial. Isso significa um crescimento mais acentuado da parcela idosa da população em comparação com os demais segmentos etários. ${ }^{1,2} \mathrm{O}$ crescimento da população idosa traz mudanças e desafios para a sociedade em todos os aspectos, tanto sociais, políticos, econômicos e culturais quanto naqueles que se referem à saúde. Este último aspecto talvez seja o mais enfatizado e preocupante, já que a maioria dosidosos apresenta ao menos uma doença crônica e limitações de saúde. ${ }^{2,3}$

Com relação ao processo do envelhecimento, torna-se difícil estabelecer um único conceito, devido à variedade de defini- ções existentes, cada qual enfocando diferentes aspectos. No sentido biológico, envelhecer é entendido como um processo natural (irreversível) e progressivo, que faz parte do ciclo da vida do ser humano pois se inicia com a concepção e culmina com a morte, passando pelas etapas de desenvolvimento intra-uterino, nascimento, infância, adolescência, maturidade e velhice. ${ }^{4} \mathrm{Tem}$-se ainda, o processo de envelhecimento como um fenômeno complexo que submete o organismo a inúmeras alterações anatômicas, fisiológicas e psicossomáticas, afetando sua integridade, permitindo o surgimento das doenças crônico-degenerativas e predispondo a uma maior morbi-mortalidade. ${ }^{5}$

Dentre os órgãos e sistemas do organismo humano que sofrem essas alterações, o 
sistema imunitário é um dos mais atingidos no envelhecimento, sofrendo modificações nas subpopulações celulares, nos padrões de secreção de citocinas, na tolerância imunológica, entre outras funções. Por ser um sistema relacionado à homeostase do organismo, faz-se necessário entender possíveis causas, bem como potenciais conseqüências que possam estar associadas às alterações imunológicas observadas entre idosos quando comparados com indivíduos jovens, alterando desta forma o equilíbrio do organismo humano.

\section{IMUNOSSENESCÊNCIA}

Sabe-se que, com relação ao processo de envelhecimento, existem na literatura variáveis que são divergentes e que ainda estão sendo estudadas para se entenda melhor esse processo. Uma das mais intrigantes é o perfil do funcionamento do sistema imunológico de um indivíduo idoso, para o qual a literatura apresenta uma visão consensual de que ele se torna menos eficiente. ${ }^{6}$ Entretanto, outros estudos sugerem uma reestruturação dos componentes do sistema imunológico no envelhecimento, podendo levar em alguns casos a funções aumentadas ou diminuídas. ${ }^{7} \mathrm{O}$ sistema imunitário pode ser afetado por condições nutricionais inadequadas, níveis exagerados de estresse, doenças e outros fatores, os quais vão se alterando com o envelhecimento e que por muitas vezes comprometem a funcionalidade do mesmo.

O termo imunossenescência usualmente refere-se às disfunções do sistema imuni- tário relacionadas com a idade que contribuem para uma maior incidência de doenças infecciosas ou mesmo crônico-degenerativas, tais como hipertensão, reumatismo, aterosclerose, coronariopatias, todas prevalentes na população de idosos. ${ }^{7} \mathrm{Na}$ atualidade, acredita-se que não apenas doenças, mas também achados clínicos comumente envolvidos com o envelhecimento, tais como a perda de massa muscular, o aumento dos níveis plasmáticos de proteínas de fase aguda e a diminuição sérica de microelementos essenciais, sejam conseqüências de desequilíbrios. ${ }^{8}$

Apesar de todas as células imunologicamente ativas poderem exibir alterações relacionadas à idade, os linfócitos T são as células efetoras da resposta celular que mais sofrem os efeitos do envelhecimento. Uma das características do sistema imunitário do idoso é a involução do timo, que sofre uma alteração histológica, uma vez que o tecido linfóide é gradualmente substituído pelo tecido adiposo, o que provoca diminuição progressiva na capacidade de proliferação de linfócitos T. ${ }^{9}$ Com o envelhecimento, uma outra alteração que ocorre no sistema imunológico é o aumento na proporção das células de memória, quando comparadas com as células virgens, o que conseqüentemente diminui a ação de defesa contra novos antígenos e pode deixar o organismo mais vulnerável. ${ }^{5}$

Outra possível explicação para um esgotamento das funções imunológicas consiste na senescência replicativa dos linfócitos estado em que as células cessam o processo 
de divisão celular devido ao encurtamento da região final dos telômeros, conseqüência do próprio processo de divisão celular. ${ }^{7}$ Essas células senescentes refletem um processo normal de envelhecimento celular pelo qual as células encurtam os telômeros a cada ciclo de divisão celular até chegarem a um impedimento da proliferação mitótica. $\mathrm{O}$ número das divisões celulares depende da espécie, da idade e do conjunto genético do indivíduo. Isso pode explicar o fato de células de pessoas jovens serem capazes de um número maior de divisões do que as células de indivíduos idosos. ${ }^{10}$

Outro tipo celular fundamental para a resposta imunológica são os linfócitos $B$. Estes, por sua vez, não apresentam alterações significativas em termos de funções e de variações numéricas no sangue periférico de indivíduos idosos. Suas modificações estão relacionadas com as alterações sofridas pelos linfócitos T, que apesar de serem células morfologicamente diferentes, realizam suas funções em conjunto. As modificações em nível de anticorpos também são pouco significativas e por vezes contraditórias, no que diz respeito ao aumento ou diminuição das imunoglobulinas. Além disso, o envelhecimento também está associado a um aumento dos níveis de auto-anticorpos na circulação, principalmente IgM e IgG. Há um aumento na freqüência da auto-reatividade, que parece originar-se na diminuição do potencial de regulação imune. ${ }^{5}$

A célula NK (Natural Killer) é outro tipo celular que também apresenta divergências entre os achados na literatura. São linfó- citos granulares que expressam em sua superfície receptores como CD56 e CD16, e que possuem a função de lisar determinados tumores e células infectadas por vírus sem a necessidade de uma sensibilização prévia. Com o envelhecimento, o número de células NK aumenta, mas não a sua atividade citotóxica. ${ }^{11}$

\section{CITOCINAS}

O sistema imunológico apresenta, em sua composição, proteínas responsáveis pela mediação das respostas imunológicas, tornando-as mais eficazes. São as citocinas, proteínas reguladoras, de baixo peso molecular, produzidas por diferentes tipos celulares e que agem de maneira autócrina, parácrina e endócrina em resposta a inúmeros estímulos. Interagem com as células através de receptores específicos de alta afinidade, $\mathrm{e}$ exercem suas funções em concentrações baixas, da ordem de picomolar. As citocinas regulam a intensidade e a duração da resposta imunológica por meio da estimulação ou da inibição da ativação, proliferação e/ou diferenciação de várias células e através da regulação da secreção dos anticorpos ou outras citocinas. ${ }^{12}$

Existem determinadas características inerentes às citocinas, são elas: 1) pleiotropia uma única citocina exercendo diferentes efeitos biológicos em diferentes tipos celulares; 2) redundância - duas ou mais citocinas que desempenham as mesmas funções; 3) sinergismo - o efeito combinado de duas ou mais citocinas é maior do que as ações somadas 
das citocinas individuais; 4) antagonismo os efeitos de uma citocina inibem ou compensam os efeitos de outra citocina; 5) indução em cascata - as ações de determinada citocina em suas células-alvo são responsáveis por estimular a produção de outras citocinas. Essas características permitem que as citocinas regulem a atividade celular e a resposta imunológica de forma coordenada e interativa.

Em regra, citocinas ligam-se a receptores específicos nas membranas das células-alvo, desencadeando vias de transdução de sinais que induzem expressão gênica. ${ }^{12} \mathrm{~A}$ formação do complexo IL-6/IL-6R, por exemplo, associa-se com glicoproteínas ligantes denominadas gp80 e gp130. Desta forma, desencadeiam-se processos intracelulares de crescimento e diferenciação. ${ }^{13}$

São descritos na literatura diferentes tipos e famílias de citocinas, com funções que influenciam direta ou indiretamente o sistema imunológico. Dentre as citocinas de caráter pró-inflamatório, a interleucina 1 (IL-1), a interleucina 6 (IL-6) e o fator de necrose tumoral (TNF- $\alpha$ ) podem ser enumeradas como as de maior destaque. Além disso, a interleucina-2 (IL-2) e o interferon- $\gamma$ (INF-y) também estão relacionados com as funções efetoras da resposta imunológica de ativação e proliferação celular.

O balanço de citocinas no organismo também sofre alterações com o processo de envelhecimento, possivelmente por quebra da homeostase de sua produção e liberação. Esse desequilíbrio pode ser exemplificado pela queda dos níveis plasmáticos de IL-2 e um aumento na produção da IL-6 com o envelhecer. ${ }^{14}$ Com a baixa proliferação dos linfócitos T, ocorre uma diminuição na produção da interleucina-2 (IL-2), importante fator de crescimento para linfócito T, bem como uma redução da forma solúvel do seu receptor específico (sIL-2R) quando comparados com a produção deste fator em células de indivíduos jovens. ${ }^{9}$

Esses achados estão diretamente relacionados com o fenômeno do inflammaging, que figura como outra importante característica do processo de imunossenescência. Definido como um estado de atividade inflamatória basal que pode ser conseqüência tanto de um estresse antigênico crônico quanto de uma maior produção idiopática de citocinas pró-inflamatórias, pode implicar o aparecimento das doenças crônicas. ${ }^{15}$ Enquanto processo inflamatório característico do envelhecimento, o inflammaging aparenta ser uma propensão progressiva a um estado pró-inflamatório fortemente influenciado pela genética ${ }^{16}$ e pelo estado energético-metabólico exibido pelo organismo. ${ }^{17}$ Ademais, a hipótese do inflammaging ganhou robusto subsídio com o desvendamento do papel supressor dos linfócitos $\mathrm{T}$ reguladores (CD4+CD25+). Ensaios funcionais dão conta de uma redução marcante da ontogênese e da funcionalidade deste tipo celular com o envelhecimento, ${ }^{18}$ o que pode justificar a reduzida eficiência do sistema imunológico, a reatividade inespecífica e a elevada prevalência de quadros autoimunitários em idosos. 


\section{FATOR DE NECROSE TUMORAL-ALFA (TNF- $\alpha$ )}

O fator de necrose tumoral alfa (TNF- $\alpha$ ), por ser uma citocina com propriedade próinflamatória, encontra-se envolvido com indução de outras citocinas (IL-6 e IL-1, por exemplo), aumento da permeabilidade vascular, ativação de monócitos e neutrófilos e a destruição direta de células infectadas ou malignas. É uma das principais citocinas mediadoras do choque séptico bacteriano, sendo sua produção estimulada por bactérias gram-negativas. Além disso, pode desempenhar também importante papel na resposta imunológica desencadeada por outros organismos infecciosos.

TNF- $\alpha$ tem sua produção a partir de macrófagos e mastócitos, tendo como principal alvo as células tumorais e as células inflamatórias. O principal estímulo para sua liberação são os lipopolissacarídeos (LPS), moléculas também chamadas de endotoxinas, derivadas da parede celular bacteriana. Entretanto, ativação de células NK e de linfócitos $T$ também pode contribuir para a produção desta citocina. Desta forma, TNF- a é importante mediador da imunidade inata, assim como da imunidade adquirida, e um elo de ligação entre as respostas imunológicas específicas e as respostas de fase aguda. ${ }^{12} \mathrm{Em}$ regra, a literatura científica aponta que leucócitos de indivíduos idosos produzem maior concentração do TNF- $\alpha$ após indução com LPS, quando comparados com os leucócitos de indivíduos jovens. ${ }^{6,9}$ No entanto, a questão permanece contestável, haja vista relatos em contrário. ${ }^{5}$
Já que variações nas freqüências alélicas na região promotora dos genes das citocinas podem ser relacionadas com sua produção e liberação, os polimorfismos de nucleotídeo único (single nucleotide polymorphisms SNPs) na região promotora do TNF- $\alpha$ vêm sendo associados com uma maior suscetibilidade a doenças de caráter inflamatório.? Um estudo sugere que a variante alélica A do polimorfismo da -308 da região promotora do TNF- $\alpha$ influencia na resistência à insulina, no percentual de massa gorda e aumenta os níveis séricos de leptina. ${ }^{19}$ Entretanto, as pesquisas relacionando polimorfismo alélico e concentrações séricas de TNF- $\alpha$ ainda são recentes $\mathrm{e}$, por vezes, conflitantes em seus achados, sendo necessária a realização de mais estudos para confirmação da influência desses polimorfismos no processo de imunossenescência.

\section{INTERFERON-GAMA (INF-Y )}

Interferon-gama (IFN-y) desempenha importante papel na regulação da resposta imunológica celular. Similarmente à IL-2, INF-Y está relacionado com funções efetoras da resposta imunológica de ativação e proliferação celular, ações características de células do perfil $\mathrm{T}_{\mathrm{H}} 1$ de linfócitos auxiliares. É produzido principalmente por células $\mathrm{T}_{\mathrm{H}} 1$ e células NK. Possui como principais funções biológicas a ativação metabólica de macrófagos estimulando atividade antimicrobicida, expressão de MHC de classe II e ativação de células NK para secreção de IL-12 que promove a diferenciação de 
células $T_{H}$ em células $T_{H} 1 .{ }^{20} \mathrm{INF}-\mathrm{Y}$, em associação com a IL-2, tem a capacidade de ativar células $\mathrm{CD} 8+$, as quais têm como principal função a atividade citotóxica antígeno-específica.

Conforme estudos descritos na literatura, idosos possuem capacidade reduzida de produzir INF-Y. Essa capacidade reduzida pode ser um dos principais pontos de diminuição da atividade citotóxica dos linfócitos, aumentando assim a probabilidade de se desenvolver infecções e neoplasias. ${ }^{9}$ Assim como outras citocinas, a regulação da expressão do INF-Y também apresenta um controle a nível transcricional. Polimorfismos na região promotora do gene são responsáveis por influenciar a atividade e interferir nas ações biológicas dessa citocina. Estudos imungenéticos sobre o INF-Y têm ênfase sobre a variação $+874 \mathrm{~T} \rightarrow$ A que foi associada com produção diferencial da citocina in vivo. ${ }^{21}$ No entanto, permanece por ser mais bem investigada a relação entre as concentrações séricas dessa citocina e o desenvolvimento de distúrbios de saúde.

\section{INTERLEUCINA-6 (IL-6)}

Entre os mediadores inflamatórios circulantes, a IL-6 é considerada um dos mais importantes, sendo amplamente estudada por associação a distúrbios crônicos (quadro 1). Para estudiosos da senescência biológica, ela é chamada de "citocina do envelhecimento" e seus níveis séricos normalmente encontramse elevados com o avançar da idade. ${ }^{6}$
IL-6 é uma citocina com características estruturais pertencente à família da hematopoietina, com massa molecular inferior a $30 \mathrm{kDa} .{ }^{12} \mathrm{Tem}$ a sua síntese a partir de linfócitos $\mathrm{T}$ e macrófagos, podendo também ser produzida a partir do tecido adiposo. ${ }^{22}$ Em seres humanos, encontra-se IL-6, sendo ainda produzida a partir de células endoteliais vasculares, fibroblastos e outras células em resposta à IL-1 e ao TNF- $\alpha .{ }^{12}$

Participa da homeostase dos sistemas neuro-endócrino e imunitário por desempenhar importantes papéis nas reações de fase aguda, na resposta ao estresse e no equilíbrio entre as vias pró-inflamatórios e antiinflamatórios. ${ }^{23}$ Como exemplificação de sua influência na resposta de fase aguda, pode-se ressaltar sua ação promotora da síntese de proteínas plasmáticas, como o fibrinogênio por hepatócitos. Ademais, IL-6 age, isoladamente ou de forma auxiliar, na proliferação, diferenciação, crescimento e atividade de diferentes tipos celulares tais como células mielóides, megacariócitos, osteoclastos, células neurais e hepatócitos. ${ }^{12,24}$ Pode funcionar também como um fator de crescimento para as células $\mathrm{B}$ durante o processo de diferenciação desses linfócitos. Similarmente, pode agir como fator de crescimento para algumas células plasmáticas malignas que crescem independentemente e secretam IL-6 como um fator de crescimento autócrino. ${ }^{12}$

$\mathrm{Na}$ atualidade, a literatura científica comporta evidências de associação dos níveis de IL-6 com entidades clínicas que representam agravos à saúde característicos do envelheci- 
Quadro 1 - Estudos que apontam associação de níveis ou genótipos de IL-6 com doenças crônicas apresentadas por idosos

\begin{tabular}{|c|c|c|c|}
\hline Estudo & Variável & Desenho & Resultado \\
\hline $\begin{array}{l}\text { Jenny et al., } \\
2002\end{array}$ & $\begin{array}{l}\text { níveis séricos e } \\
\text { polimorfismo }-174 \\
\text { G/C }\end{array}$ & $\begin{array}{l}\text { caso-controle prospectivo; } \\
5888 \text { brancos ou negros } \\
\text { norte-americanos } \geq 65 \text { anos; } \\
\text { homens e mulheres. }\end{array}$ & $\begin{array}{l}\text { níveis de IL-6 } \geq 1,27 \\
\mathrm{pg} / \mathrm{ml} \text { associados com } \\
\text { maior incidência de fatores } \\
\text { de risco cardiovascular } \\
\text { (idade, IMC, insulinemia, } \\
\text { hipertensão arterial e } \\
\text { hipertrofia ventricular). }\end{array}$ \\
\hline $\begin{array}{l}\text { Kado et al., } \\
1999\end{array}$ & níveis séricos de IL-6 & $\begin{array}{l}\text { caso-controle transversal; } \\
57 \text { diabéticos tipo II (23-77 } \\
\text { anos) e } 15 \text { normoglicêmicos ( } 25- \\
76 \text { anos) japoneses. }\end{array}$ & $\begin{array}{l}\text { nível elevado de IL }-6 \\
(\bar{x}=3,48 \mathrm{pg} / \mathrm{ml}) \\
\text { associado com maior } \\
\text { prevalência de diabetes } \\
\text { mellitus. }\end{array}$ \\
\hline $\begin{array}{l}\text { Bonafè et al., } \\
2001\end{array}$ & $\begin{array}{l}\text { polimorfismo }-174 \\
\text { G/C }\end{array}$ & $\begin{array}{l}\text { corte transversal; } \\
482 \text { mulheres } \\
\text { e } 218 \text { homens italianos; } \\
60-110 \text { anos }\end{array}$ & $\begin{array}{l}\text { proporção de homozigotos } \\
\text { G decresce em centenários } \\
\text { mas não em centenárias, } \\
\text { implicando maior } \\
\text { predisposição genética à } \\
\text { produção de IL-6 com } \\
\text { desvantagem para } \\
\text { longevidade. }\end{array}$ \\
\hline $\begin{array}{l}\text { Forsey et al., } \\
2003\end{array}$ & níveis séricos de IL-6 & $\begin{array}{l}\text { caso controle transversal; } \\
138 \text { idosos suecos com idades = } \\
86 \text { ou } 94 \text { anos, e } \\
18 \text { controles entre } 32 \text { e } 59 \text { anos; } \\
\text { homens e mulheres. }\end{array}$ & $\begin{array}{l}\text { nível mais elevado de IL - } 6 \\
(\bar{x}=3,16 \mathrm{pg} / \mathrm{ml}) \text { entre os } \\
\text { idosos; no grupo dos } \\
\text { idosos, dosagens foram } \\
\text { mais acentuadas naqueles } \\
\text { que exibiam saúde } \\
\text { classificada como frágil. }\end{array}$ \\
\hline $\begin{array}{l}\text { Licastro } \\
\text { et al., } 2003\end{array}$ & $\begin{array}{l}\text { polimorfismo }-174 \\
\text { G/C }\end{array}$ & $\begin{array}{l}\text { caso controle transversal; } \\
332 \text { idosos italianos portadores } \\
\text { de Alzheimer ( } \bar{x}=71 \text { anos) e } \\
393 \text { não portadores ( } \bar{x}=76 \\
\text { anos); homens e mulheres. }\end{array}$ & $\begin{array}{l}\text { nível de IL-6 plasmática } \\
\text { significativamente maior } \\
\text { em portadores de } \\
\text { Alzheimer dos genótipos } \\
\text { CC e GC. }\end{array}$ \\
\hline $\begin{array}{l}\text { Tonet et al., } \\
2008\end{array}$ & $\begin{array}{l}\text { níveis séricos e } \\
\text { polimorfismo }-174 \\
\text { G/C }\end{array}$ & $\begin{array}{l}\text { corte transversa } 1 \text {; } \\
193 \text { mulheres brasileiras ? } 60 \\
\text { anos; diversas co-morbidades. }\end{array}$ & $\begin{array}{l}\text { casos de hipertensão } \\
\text { arterial e intolerância à } \\
\text { glicose mais prevalentes } \\
\text { entre portadores do alelo } \\
\text { G, com leve tendência a } \\
\text { exibirem maior nível } \\
\text { sérico de IL-6. }\end{array}$ \\
\hline
\end{tabular}


mento, tais como: perda de massa corporal magra, anemia, osteopenia, diminuição da albumina sérica e aumento de proteínas inflamatórias (Proteína CReativa e Amilóide A). ${ }^{25}$

No que se refere ao perfil de morbidades prevalentes e impactantes para a saúde na terceira idade, cabe ressaltar trabalhos que apontam para um maior nível sérico de IL6 entre idosos com desordens linfoproliferativas, mieloma múltiplo, doenças de Alzheimer e osteoporose, ${ }^{24}$ bem como aqueles estudos que associam IL-6 com maior declínio funcional e mortalidade acentuada do indivíduo. ${ }^{26,27}$

Acredita-se que determinados polimorfismos do gene de IL-6 estão associados a uma maior produção deste mediador inflamatório, sendo sua produção geneticamente influenciada e dependente da idade e do gênero. ${ }^{28,29}$ Sugere-se então que essas variações alélicas possam ao menos em parte explicar a suscetibilidade às doenças, uma vez que podem vir acompanhadas pelo aumento dos níveis séricos de IL-6. O polimorfismo do gene da IL-6 vem sendo estudado e associado com a presença de várias doenças agudas e crônicas, sendo o SNP na posição -174 o principal foco das pesquisas. Além dele, existem outros pontos singulares de polimorfismo na região promotora da IL-6, a saber, as variações $-597 \mathrm{G} / \mathrm{A}$ e $-572 \mathrm{G} / \mathrm{C}$. No entanto, essas variações se encontram em desequilíbrio de ligação com o polimorfismo - $174 \mathrm{C} / \mathrm{G}$, de modo a se convencionar o estudo deste último. ${ }^{30-32} \mathrm{~A}$ literatura apresenta controvérsias no que diz respeito à relação do polimorfismo com os aumentos séricos desta proteína. Existem estudos que indicam a presença dessa associação entre o polimorfismo $-74 \mathrm{C} / \mathrm{G}$ e o aumento da IL-6 sérica. ${ }^{28,30,33}$ Por outro lado, existem estudos que não identificaram essa relação em seus resultados, ${ }^{31,32}$ possivelmente em decorrência de uma variabilidade no background genético entre etnias.

Acredita-se que essa mudança de bases $\mathrm{G} \rightarrow \mathrm{C}$ na posição -174 afeta a transcrição do gene, podendo alterar os níveis plasmáticos da IL- $6,{ }^{34}$ podendo ter significado relevante na suscetibilidade a determinadas patologias nos idosos. Com relação à Doença de Alzheimer, existe uma importante relação entre a presença do alelo $\mathrm{C}$ com o aumento do risco de desenvolver a patologia. ${ }^{35}$ Sobretudo, o polimorfismo - $174 \mathrm{C} / \mathrm{G}$ parece estar relacionado com o aumento do risco das doenças cardiovasculares (CVD) em idosos. ${ }^{36}$ Neste caso, o alelo C parece desempenhar um importante papel, principalmente no desenvolvimento da aterosclerose. No caso da patologia da osteoporose, sugere ainda que o polimorfismo pode ser importante fator de risco para o desenvolvimento da doença em mulheres idosas. ${ }^{37}$ A artrite reumatóide é outra patologia que sofre influência do polimorfismo da IL-6. Um estudo demonstrou que pacientes com genótipo GG têm a forma ativa da artrite reumatóide mais freqüentemente que pacientes portadores dos demais genótipos, propondo-se, assim, que o polimorfismo na região promotora da IL-6 pode ser um fator de risco para artrite reumatóide. ${ }^{38}$ 
São inúmeros os estudos encontrados na literatura que relacionam o polimorfismo na posição $-174 \mathrm{C} / \mathrm{G}$ da região promotora da IL-6 com a maior suscetibilidade a diferentes doenças. Entretanto, os resultados apresentam controvérsias e são conflitantes. A disparidade de resultados é conseqüência dos estudos ainda a serem realizados entre diferentes grupos étnicos e por métodos diversificados, não apresentando padrões de comparação. Diante desse quadro inconstante de achados, torna-se necessário um número maior de pesquisas enfocando o polimorfismo da IL-6 e relacionando-a com a suscetibilidade ao desenvolvimento de patologias.

\section{IL-6 E DABEIESMEUTUS TIPO 2 (DM2)}

Como visto anteriormente, uma resposta imunológica caracteriza-se por elevados níveis sangüíneos de marcadores de resposta de fase aguda, destacando-se, entre eles, a IL-6. Pelo fato de esta citocina também se apresentar em maior concentração em pacientes com diabetes mellitus tipo 2 (DM2), entende-se na atualidade que essa patologia possui componente etiológico decorrente de inflamação sistêmica subclínica, podendo ser atribuída também a um desequilíbrio do sistema imunológico inato. ${ }^{39} \mathrm{O}$ estresse crônico provocado no sistema imunitário pode ocasionar o declínio da sensibilidade à insulina, contribuindo para o desenvolvimento da DM2. ${ }^{40,41}$ Excesso de TNF- $\alpha$, por exemplo, induz diminuição sistêmica na produção de receptores para insulina, que contribui para um estado de resistência à ação do hormônio. ${ }^{42}$ Esse mecanismo pode explicar a resistência insulínica observada na obesidade, uma vez que a massa gorda secreta TNF- $\alpha$.

Em consonância com o TNF-a, os níveis séricos da IL-6 estão elevados em casos de obesidade, e relacionados com a sensibilidade à insulina. ${ }^{43}$ Além disso, altas concentrações sangüíneas dessa citocina podem funcionar como prognóstico de desenvolvimento da DM2. ${ }^{44} \mathrm{E}$ quando comparados os níveis de IL-6 entre pacientes diabéticos e normais, os estudos mostram valores maiores de IL-6 sérica para os portadores da patologia. ${ }^{33,41,45}$

Sob o aspecto genético, a presença de SNPs na região promotora do gene da IL-6 sugere que certos alelos podem ser considerados fatores de risco para o desenvolvimento da DM2. ${ }^{30} \mathrm{~A}$ distribuição dos genótipos da IL-6 é significativamente diferente entre indivíduos diabéticos e não-diabéticos, pois o genótipo GG é predominante em pacientes portadores de DM2, quando comparados com pacientes não-diabéticos. ${ }^{41}$ Já o genótipo CG aparece em pacientes diabéticos, mas com uma freqüência bem menor, quando comparado ao genótipo GG. Em outro estudo realizado, ${ }^{46}$ mas com pacientes não-diabéticos, identificou-se um genótipo $\mathrm{C} / \mathrm{C}$ em pacientes que apresentavam características de alta sensibilidade à insulina, um dos fatores responsáveis pelo desenvolvimento da patologia. Estudo realizado com a população brasileira também corrobora a associação do alelo $\mathrm{G}$ com o fenóti- 
po da intolerância à glicose. ${ }^{47} \mathrm{~A}$ comparação entre os estudos torna-se difícil pelo fato de os grupos de pessoas estudadas diferirem em idade, sexo, grau de obesidade e tolerância à glicose, tornando os resultados de difícil interpretação.

\section{IL-6 E DOENÇAS CARDIOVASCULARES (DCV)}

Semelhante à DM2, as doenças cardiovasculares como a aterosclerose e o infarto agudo do miocárdio também são considerados fenômenos inflamatórios, nos quais o sistema imunológico desempenha importante função pela produção exacerbada de mediadores pró-inflamatórios. Acredita-se que a resposta inflamatória é iniciada quando citocinas inflamatórias, como IL-1, TNF-a, IL-6 são liberadas a partir de um tecido afetado. Vários estudos sugerem que o processo inflamatório desempenha importante papel na patogênese $\mathrm{da}$ aterosclerose, e que o aumento dos níveis plasmáticos de marcadores inflamatórios, como IL-6 e proteína C-reativa (PCR), podem estar relacionados com a presença da aterosclerose, infarto do miocárdio e aumento da pressão sangüínea. ${ }^{48,49}$ Sugere-se ainda que a ativação de neutrófilos, linfócitos e monócitos circulantes, associada ao aumento da concentração dessas citocinas pró-inflamatórias (II6 e IL-1) e das proteínas de fase aguda (PCR), esteja envolvida na progressão da aterosclerose e suas complicações. ${ }^{50}$

A PCR é uma importante proteína de fase aguda, com propriedades pró e antiinflamatórias, produzida principalmente pe- los hepatócitos. É considerada um sensível marcador de inflamação e de danos tissulares, os quais recentemente estão sendo relacionados como preditores de possíveis eventos arterotrombóticos. ${ }^{48}$ De acordo com a literatura, as elevadas concentrações plasmáticas de PCR em pacientes com problemas cardiovasculares refletem o aumento da atividade inflamatória, predizendo rápida progressão da patologia. ${ }^{51}$ Como a PCR tem sua síntese induzida e regulada principalmente pela IL-6, essas proteínas podem agir em conjunto como marcadores inflamatórios. O uso combinado dos níveis plasmáticos da IL-6 e da PCR é mais preciso no prognóstico de um acidente vascular do que quando estes são analisados separadamente. ${ }^{19}$

Os estudos apresentados na literatura com relação ao polimorfismo do gene da IL-6 e a suscetibilidade às doenças cardiovasculares ainda não são conclusivos. Esses estudos também apresentam controvérsias, principalmente quando contribuições adversas como tabagismo, alcoolismo, obesidade e hipertensão são considerados, já que eles influenciam diretamente no desenvolvimento da patologia.

\section{CONCLUSÃO}

O processo de imunossenescência vem sendo estudado sob aspectos celulares, moleculares e genéticos, com o objetivo de prognosticar doenças e intervir na prevenção das mesmas. Uma das principais características observadas com o envelhecimento do sistema imunitário é a relação entre a 
produção de mediadores inflamatórios e o surgimento de doenças prevalentes nos idosos. Por essa razão, postula-se que, à medida que sua contribuição para o processo de senescência seja elucidada, essas moléculas venham a constituir novo grupo de marcadores para doenças crônico-degenerativas.

Entretanto, deve-se ressaltar que existem controvérsias nos resultados descritos na literatura, provavelmente pela dificuldade de se padronizar os estudos e pela grande estruturação genética que existe na humanidade. Além disso, o processo inflamatório pode sofrer influências de condições pertinentes ao estilo de vida como, por exemplo, a obe-

\section{REFERÊNCIAS}

1- Camarano AA, Kanso S, Mello JM. Como vive o idoso Brasileiro? In: Camarano AA. Muito além dos 60 ? Os novos idosos brasileiros. Rio de Janeiro: IPEA; 2004.

2- Chaimowicz F. A saúde dos idosos brasileiros às vésperas do século XXI: problemas, projeções e alternativas. Rev Saúde Pública 1997; 31(2): 184-200.

3- Ramos LR. Fatores determinantes do envelhecimento saudável em idosos residentes em centro urbano: Projeto Epidoso, São Paulo. Cad Saúde Pública 2003; 19 (3):793-98.

4 Freitas EV, Py L, Neri AN, Cançado FLX, Gorzoni, LM, Rocha, SM. Tratado de Geriatria e Gerontologia. Rio de Janeiro: Guanabara Koogan; 2002.

5- Luz C, Dornelles F, Preissler T, Collaziol D, Cruz IM, Bauer ME. Impact of psychological and endocrine factors on sidade, tabagismo e sedentarismo, que acabam interferindo na saúde do indivíduo.

Com relação aos polimorfismos encontrados nos genes dos mediadores inflamatórios, pode-se afirmar que eles interferem diretamente na expressão dos mesmos. Sendo assim, torna-se necessário conhecer e entender o papel das variações genéticas na inflamação e nas doenças crônicas, possibilitando identificar pessoas saudáveis que apresentam aumento do risco de doenças e potencializar a mudança de trajetória dessa doença, prolongando a longevidade e possibilitando um envelhecimento saudável. cytokine production of healthy elderly people. Mech Ageing Dev 2003;124(89):887-95.

6- Tarazona R, Solana R, Ouyang Q, Pawaelec G. Basic biology and clinical impact of immunosenescence. Exp Gerontol 2002; 37: 183-89.

7- Krabbe KS, Pedersen M, Brunsgaard H. Inflammatory mediators in the elderly. Exp Gerontol 2004; 39(5): 687-99.

8- Grimble RF. Inflammatory response in the elderly. Current Opinion Clin Nut Met Care 2003; 6: 21-9.

9- Rink L, Cakman I, Kirchner H. Altered cytokine production in elderly. Mech Ageing Dev 1998; 102: 199-209.

10- Hornsby PJ. Cellular senescence and tissue aging in vivo. J Geront 2002; 57A: B251-56. 
11- Franceschi C, Bonafè M, Valensin S, Olivieri F, De Luca M, Ottaviani E, De Benedictis G. Inflamm-aging. An evolutionary perspective on immunosenescence. Ann N Y Acad Sci 2000; 908: 244-54.

12 - Abbas AK, Lichtman AH, Pober JS. Cellular and molecular immunology. $2^{\text {nd }}$ ed. Philadelphia: W.B.Saunders Company; 1994.

13 - Streetz KL, Luedde T, Manns MP, Trautwein C. Interleukin 6 and liver regeneration. Gut 2000; 47: 309 - 12.

14. Mysliwka J, Bryl E, Foerster J, Mysliwka A. Increase of interleukin 6 and decrease of interleukin 2 production during the aging process are influenced by the health status. Mech Ageing Dev 1998; 100: 313-28.

15- Leng SX, Yang H, Walston JD. Decreased cell proliferation and altered cytokine production in frail older adults. Exp Gerontol 2004; 16: 249-52.

16- Mishto M, Santoro A, Bellavista E, Bonafe M, Monti D, Franceschi C.

Immunoproteasomes and immunosenescence. Ageing Res Rev 2003; 2(4):419-32.

17- Rudin E, Barzilai N. Inflammatory peptides derived from adipose tissue. Immun Ageing 2005;2:1.

18- Dejaco C, Duftner C, Schirmer M. Are regulatory T-cells linked with aging? Exp Gerontol 2006; 41: 339-45.

19- Ishii T, Hirose H, Saito I, Nishikaik K, Maruyama H, Saruta T. Tumor necrosis factor alpha gene G-308A polymorphism, insulin resistance, and fasting plasma glucose in young, older, and diabetic Japanese men. Metabolism 2000; 49: 1616-18.

20- Ferreira AW, Ávila SLM. Diagnóstico laboratorial das principais doenças infecciosas e auto-imunes. 2. ed. Rio de Janeiro: Guanabara Koogan; 2001.
21- Scola L, Licastro F, Chiappelli M, Franceschi C, Grimaldi LM, Crivello A, et al. Allele frequencies of $+874 \mathrm{~T}->\mathrm{A}$ single nucleotide polymorphism at the first intron of IFN-gamma gene in Alzheimer's disease patients. Aging Clin Exp Res Aug 2003;15: 292-5.

22- Mohamed-Ali V, Goodrick S, Rawesh A, Miles JM, Yudkin JS, Kleins S, et al. Subcutaneous adipose tissue releases interleukin-6, but not tumor necrosis factor-alpha, in vivo. J Clin End Met 1997; 82: 4196-200.

23- Xing Z, Gauldie J, Cox G, Baumann H, Jordana M, Lei XF, et al. IL-6 is an antiinflammatory cytokine required for controlling local or systemic acute inflammatory responses. J Clinical Invest 1998; 101: 311-20.

24 Ershler WB, Keller ET. Age-associated increased interleukin-6 gene expression, late-life diseases, and frailty. Annu Rev Med 2000; 51: 245-70.

25- Forsey R, Thompson J, Ernerudh J, Hurst T, Strindhall J, Johansson B, et al. A plasma cytokine profiles in elderly humans. Mech Ageing Dev 2003; 124: 487-93.

26- Tamara BH, Ferrucci L, Tracy RP, Corti MC, Wachoder S, Ettinger WH, et al. Associations of elevated interleukin- 6 and C-reactive protein levels with mortality in the elderly. Am J Med 1999; 106: 506-12.

27- Ferrucci L, Harris TB, Guralnik JM, Tracy RP, Corti MC, Cohen HJ, et al. Serum IL-6 level and development of disability in older persons. J Am Geriatic Soc 1999; 47: 639-46.

28- Olivieri F, Bonafe M, Cavallone L, Giovacnetti S, Marchegiani F, Cardeli M, et al. The $-174 \mathrm{C} / \mathrm{G}$ locus affect in vitro/ in vivo IL-6 production during aging. Exp Geront 2002; 37: 309-14. 
29- Christiansen L, Bathum L, AndersenRanberg K, Jeune B, Christensen K. Modest implication of interleukin-6 promoter polymorphism in longevity. Mech Aging Dev 2004; 125: 391-5.

30- Fishman D, Faulds G, Jeffery R, Mohamed-Ali V, Yudkin JS, Humphries S, et al. The effect of novel polymorphisms in the interleukin-6 (IL-6) gene on IL-6 transcription and plasma IL-6 levels, and an association with systemic-onset juvenile chronic arthritis. J Clin Invest 1998; 102: 1369-76.

31- Georges JL, Loukaci V, Poirier O, Evans A, Lug G, Arvalier D. Interleukin-6 gene polymorphisms and susceptibility to myocardial infarction the ECTIM study. J Mol Med 2001; 79: 300-5.

32- Terry CF, Loukaci V, Green FR. Cooperative influence of genetic polymorphisms on interleukin-6 trascriptional regulation. J Biol Chem 2000; 275: 1838-44.

33- Illig T, Bongardt F, Schopfer A, Huth C, Heid I, Rathmann W, et al. Significant association of interleukin-6 gene polymorphism C-174G and A-598G with type 2 diabetes. J Clin Endocrinol Met 2004; 89: 5053-8.

34- Chavez RFA, Hybki PDL, Barber RC, Keefe GE. Interleukin-6 promoter haplotypes and interleukin- 6 cytokine responses. Shock 2003; 20: 218-23.

35- Licastro F, Grimaldi LM, Bonafe M, Martina C, Olivieri F, Cavallone L, Giovanietti S, et al. Interleukin-6 gene alleles affect the risk of Alzheimer disease and levels of the cytokine in blood and brain. Neurobiol Aging 2003; 24: 921-6.

36- Jenny ST, Russel PT, Malcon SO, Luong LA, Lewis HK, Arnod AM. In the elderly, interleukin-6 plasma levels and -174G $>C$ polymorphism are associated with the development of cardiovascular disease. Arterioscler Thromb Vasc Biol 2002; 22: $2066-71$.

37- Ferrari SL, Garnero P, Emond S, Montgomery $\mathrm{H}$, Humphries SE, Greenspan SL. A functional polymorphic variant in the interleukin-6 gene promoter associated with low bone resorption in postmenopausal women. Arthrits Rheum 2001; 44: 196-201.

38- Pawlik A, Wrzesniewska J, Florczak M, Gawronska-Szklarz B, Herczynska M. IL-6 promoter polymorphism in patients with rheumatoid arthritis. Scand J Rheumat 2005; 34: 109-13.

39- Pickup JC, Crook MA. Is type II diabetes mellitus a disease of the innate immune system? Diabetologia 1998; 41: 1241-48.

40- Cardellini M, Perego L, D'Adamo M, et al. C-174G polymorphism in the promoter of the interleukin- 6 gene is associated with insulin resistance. Diabetes Care 2005; 28: 2007-12.

41- Huth C, Heid IM, Vollmert C, Gieger C, Grallert H, Wolford JK, et al. IL6 gene promoter polymorphisms and type 2 diabetes: joint analysis of individual participants' data from 21 studies. Diabetes 2006; 55: 2915-21.

42- Gabriely I, Barzilai N. The role of fat cell derived peptides in age-related metabolic alterations. Mech Ageing Dev 2001; 122: $1565-76$.

43- Bastard JP, Jardel C, Brucket E, Blondy P, Capeau J, Laville M, et al. Elevated levels of interleukin-6 are reduced in serum and subcutaneous adipose tissue of obese women after weight loss. J Clin Endocrinol Metab 2002; 85: 3338- 42.

44 Pradhan AD, Manson JE, Rifain N, Buring JE, Ridker PM. C-Reactive Protein, Interleukin 6 and Risk of 
Developing Type 2 Diabetes Mellitus. JAMA 2001; 286: 327-34.

45- Kado S, Nagase T, Nagata N. Circulating levels of interleukin-6, its souble receptor and interleukin-6/interleukin-6 receptor complexes inpatients with type diabetes mellitus. Acta Diabetol 1999; 36: 67-72.

46- Fernandez-Real JM, Broch M, Vendrei J, Gutierrez C, Casamit R, Pugeat M, et al. Interleukin-6 gene polymorphism and insulin sensitivity. Diabetes 2000; 49: 517-20.

47- Tonet AC, Karnikowski M, Moraes CF, Gomes L, Karnikowski MG, Córdova C, Nóbrega OT. Association between the -174 G/C promoter polymorphism of the interleukin- 6 gene and cardiovascular disease risk factors in Brazilian older women. Braz J Med Biol Res 2008; 41: 47-53.

48- Vitale C, Gebara O, Mercuro G, Wajngarten M, Silvestri A, Rossini P, et al.
Value of C-reactive protein levels and IL-6 in predicting events levels in women at increased cardiovascular risk. Maturitas 2005; 50: 239-46.

49- Tanaka C, Mannami T, Kamide K, Takiuchi S, Kokubo Y, Katsuya T, et al. Single nucleotide polymorphisms in the interleukin- 6 gene associated with blood pressure and atherosclerosis in a Japanese general population. Hypertens Res 2005; 28: 35-41.

50- Libby P, Ridker PM, Maseri, A. Inflammation and atherosclerosis. Circulation 2002; 105: 1135-43.

51- Marchien W, Kenemans P, Emeis JJ, Schalkwijk GG, Mijatovic V, Mooren MJ. Long-term effects of combined hormone replacement therapy on markers of endothelial funcition and inflammatory activity in healthy postmenopausal women. Fertil Steril 1999; 71: 663-70. 
1 